\title{
ADUBAÇÃo DA SERINGUEIRA NO PERÍODO DE PÓS ENXERTIA. I: RELACIONADA À DATA DE DECEPAGEM DO PORTA-ENXERTO
}

\author{
J. da P. PEREIRA \\ EMBRAPA/IAPAR - C.P. 1331 - CEP: 86001-000-Londrina,PR. \\ A.A. LUCCHESI \\ Departamento de Bolânica - ESALQ/USP - C.P. 9 - CEP: 13418-900-Piracicaba,SP. \\ R.I. SILVEIRA \\ Departamento de Ciencia do Solo - ESALQUUSP - C.P. 9 - CEP: 13418-900-Piracicaba,SP.
}

\begin{abstract}
RESUMO: Com o objetivo de obter informaçōes, que visem solucionar o grave problema de desuniformidade na brotação da gema do enxerto e do crescimento atrofiado desta após a decepagem da parte aérea do porta-enxerto, foram aplicados $N$ e $K$ na presença e ausência de $P$, em adubações-regulares e variáveis, em diferentes datas antes e após a decepagem da parte aérea do porta-enxerto (mudas formadas diretamente em sacos de plástico). A adubação no periodo de pós-enxertia, mostrou-se extremamente necessária para o crescimento e vigor das mudas. Em relação à época, a adubação feita na data da decepagem do porta-enxerto, não apresentou resultados satisfatórios. $A$ antecipação na emissão, uniformidade e vigor do $1^{\circ}$ lançamento foliar, foram obtidos quando as plantas foram adubadas aos 15 dias antes da decepagem e eliminação da parte aérea do porta-enxerto. As maiores taxas de crescimento e uniformidade das plantas e vigor do $2^{\circ}$ lançamento, ocorreram nas plantas adubadas com NPK, aos 30 dias apos a decepagem do porta-enxerto.
\end{abstract}

Descritores: seringueira, adubação, decepagem, porta-enxerto, pós-enxertia.

\section{EFFECT OF APPLYING FERTILIZERS TO RUBBER SEEDLINGS AFTER GRAFTING AS RELATED TO TIME OF ROOT STOCK PRUNING}

\begin{abstract}
Nitrogen and potassium were applied with and withoult phosphorus to rubber seedlings at various rates and intervals prior to and after root stock pruning in an attempt to observe budding uniformity and stunting. The use of fertilizers pos-grafting was effective in promoting seedling growth and vigor. Uniformity, vigor and precocity of first whorl was related to fertilizing stocks 15 days prior to pruning, but the better at the 2nd whorld stage was obtained in stocks receiving NPK 30 days after pruning.
\end{abstract}

Key Words: rubber-tree, fertilization, pruning, root stock, pos-grafting.

\section{INTRODUÇÃO}

A heveicultura no Brasil encontra-se, nos dias atuais, em franca expansão, ultrapassando, de há muito, as fronteiras da Amazônia, seu habitat natural e as áreas tradicionais do litoral do sul da Bahia. A cultura vai ganhando espaço nas áreas consideradas de escape ou não tradicionais, atingindo os Estados de São Paulo, Minas Gerais, Mato Grosso, Mato Grosso do Sul, Espírito Santo, Maranhão, Zona da Mata de Pernambuco, Noroeste do Paraná, Região dos Lagos do Estado do Rio de Janeiro (BUENO, 1986; PEREIRA, 1990; VIEGAS, 1985).

A despeito das condições edafoclimáticas bastante diferenciadas nessas áreas, a seringueira vem se desenvolvendo de modo bastante satisfatório, embora existam algumas dúvidas quanto ao melhor preparo, manejo e adubação inicial das mudas, visando a formação de seringais de cultivo.

$\mathrm{Na}$ cultura da seringueira, os estudos sobre a nutrição não tem merecido a devida atenção no Brasil (VIEGAS, 1991).

Nos últimos anos, devido à grande expansão da cultura, alguns trabalhos nessa área foram realizados (AMARAL, 1983; GUERRINI, 1983; HAAG et al. 1986; BUENO, 1987).

Porém, a existência de informações acerca da adubação e nutrição da seringueira, na fase de produção de mudas é muito pequena no Brasil (PRADO \& MORAES, 1969; REIS et al., 1977; IPEAN, 1973; VALOIS \& BERNIZ, 1984; VIEGAS \& CUNHA, 1980; BUENO et al., 1984).

A aplicação padronizada de fertilizantes não formulados em viveiros, em condições de 
campo é uma prática bastante conhecida (RUBLER RESEARCH INSTITUTE OF MALASIA, 1983); contudo, não há referência de trabalhos sobre a adubação no período pós-enxertia.

Do mesmo modo, a aplicação em mudas produzidas diretamente no saco de plástico, parece inadequadamente estudada, face à ausência de trabalhos publicados a esse respeito, principalmente sobre quando, quanto e como adubar em relação ao tempo de decepagem da parte aérea do portaenxerto. objetivos:

O trabalho foi realizado, com os seguintes

- Eliminar a desuniformidade na brotação e crescimento atrofiado da gema do enxerto, mediante:

a) Aplicação de NPK na forma líquida, testando o uso de seringa aplicadora $e$,

b) Uso de adubações regulares e variáveis, em relação à data de decepagem da parte aérea do porta-enxerto envolvendo NK na presença e ausência de $\mathbf{P}$.

\section{MATERIAL E MÉTODOS}

O experimento foi realizado em propriedade pertencente ao Grupo Sasazaki, Latex Agrícola Lida, Fazenda Santa Helena, em MariliaSP.

Os porta-enxertos foram obtidos a partir de mistura de sementes clonais ilegítimas de Tjir 1 , Tjir 16 ou Ga 1328 , cujas plântulas, recémgerminadas, foram repicadas para sacos de plástico, com capacidade para $5 \mathrm{~kg}$ de terra.

O solo usado para enchimento dos sacos é o Podzólico, variação Marilia, representativo da região (QUEIROZ NETO \& TORNAUX, 1978; BARROS, 1985), com boas propriedades físicas e regulares propriedades químicas (TABELA 1).

A enxertia (clone PB 235), foi feita quando as mudas enviveiradas a pleno sol, apresentavam 18 meses e $1,80 \mathrm{~cm}$ de diâmetro, a $5 \mathrm{~cm}$ do solo. $O$ enxertos vivos após a primeira verificação e repasse, constituiram-se no material trabalhado.

As adubações foram feitas a intervalos regulares de 15 dias, em relação à data de decepagem dos porta-enxertos, perfazendo um total de cinco grupos distintos.
Quinze dias antes da decepagem (- 15 dias), foi feita a adubação do primeiro grupo de plantas.

Decorridos 15 dias dessa adubação, foi feita a decepagem geral da parte aérea dos portaenxertos, incluindo a poda das raízes que ultrapassaram o fundo dos sacos e feita a dubação completa do segundo grupo ( $0 \mathrm{dia})$.

Nessa mesma ocasião, um outro grupo de mudas recebeu adubação correspondente à metade das dosagens usadas, ficando a outra metade para ser adubada 30 dias após, constituindo o tratamento 0 - 30 dias).

Do mesmo modo, outros dois grupos de plantas, adubadas aos 15 e aos 30 dias após a decepagem geral, constituíram os tratamento $(+15$ dias e $+\mathbf{3 0}$ dias), deixando-se tambem um grupo de 48 plantas como controle (Testemunha sem adubação).

As adubações foram feitas com $\mathrm{N}$ e K por via líquida, nas concentrações de 100 ppm $(0-30$ dias) e $200 \mathrm{ppm}$ os demais tratamentos, na presença e ausência de $P$, aplicado a $70 \mathrm{ppm}$.

A metodologia de aplicação dos fertilizantes, por via líquida, envolveu o uso de seringa dosadora automática, marca Hoppner, normalmente usada para vacinação de bovinos, graduando-se o percurso do êmbulo para $5 \mathrm{~cm}(5$ $\mathrm{ml}$ ) a cada compressão feita no gatilho, representando exatamente $10 \mathrm{ml}$ aplicados em dois movimentos.

Nitrogênio (N) - Como fonte nitrogenada, foi usado nitrocálcio $(27 \% \mathrm{~N})$ na base de $3,70 \mathrm{~g}$ por planta (saco com $5 \mathrm{~kg}$ de terra), nos tratamentos sem adubação fosfatada e 3,13 g por planta, nos tratamentos que receberam adubação fosfatada.

Fósforo (P) - Como fonte de fósforo, foi usado fosfato monoamónico (MAP), finamente moído, que, além de $\mathrm{P}$, contém $10 \%$ de $\mathrm{N}\left(\mathrm{NH}_{4}\right)$ equivalente a $154,2 \mathrm{mg}$ de $\mathrm{N}$, deduzidos do nitrogênio aplicado como nitrocálcio; nos tratamentos que receberam o fósforo. A quantidade de $P$ aplicada na forma de MAP, foi de 1,606g por saco de $5 \mathbf{~ k g}$ de terra.

Potássio (K) - A exemplo de N, as quantidades de potássio aplicadas por $\mathrm{kg}$ de terra, foram de 100 ppm e 200 ppm de $\mathrm{K}_{2} \mathrm{O}$, o que correspondeu a 1,0 g e 2,0 g do produto por planta, previamente moído para facilitar a dissolução. 
TABELA 1 - Características químicas do solo podzolizado, variação Marilia, usado no experimento (Marilia,SP, 1987).

\begin{tabular}{|c|c|c|c|c|c|c|c|c|c|c|c|c|c|}
\hline & & & \multicolumn{3}{|c|}{ RESULTADOS } & \multicolumn{2}{|c|}{ ANALITICOS } & D O & \multicolumn{2}{|c|}{ SOLO } & & & \\
\hline \multicolumn{10}{|c|}{ Meq/100 $\mathrm{cm}^{3}$} & \multicolumn{4}{|c|}{ pprn } \\
\hline $\mathbf{P}$ & M.o. & $\mathrm{pH}$ & $\mathbf{K}$ & $\mathrm{Ca}$ & $\mathbf{M}_{\mathbf{g}}$ & $\mathbf{H}+\mathbf{A l}$ & $s$ & $\mathbf{T}$ & $\mathbf{V} \%$ & $\mathrm{Cu}$ & Fe & $M n$ & $Z_{n}$ \\
\hline res. & $\Phi$ & $\mathrm{CaCl}_{2}$ & & & & & & & & & & & \\
\hline $41,1 \mathrm{a}$ & $0,87 a b$ & $5,7 a$ & $0,07 \mathrm{mb}$ & $1,89 \mathrm{~m}$ & $0,77 \mathrm{~m}$ & $1,48 b$ & $2,7 a$ & $4,2 b$ & $64,4 m$ & $0,40 \mathrm{~m}$ & $2,42 m$ & $12,1 \mathrm{~m}$ & $0,85 \mathrm{~m}$ \\
\hline
\end{tabular}

Obs: $\mathrm{mb}=$ muito baixo; $\mathrm{b}=$ baixo; $\mathrm{m}=$ médio; $\mathrm{a}=$ alto; $\mathrm{ma}=$ muito alto.

Iniciada a brotação dos enxertos, foi feito, periodicamente, um total de 7 medições da altura das plantas, diâmetro do caule a $5 \mathrm{~cm}$ do calo de enxertia e estádio fenológico dos lançamentos. Após 120 dias foi feita a última coleta de dados, além de caule, folhas e solo, colhidos separadamente para análise. O material vegetal colhido, foi lavado em água desmineralizada. acondicionado em saco de papel e colocado para secar em estufa de circulação forçada de ar, à temperatura de $70^{\circ} \mathrm{C}-75^{\circ} \mathrm{C}$, até atingir peso constante.

Após a determinação do peso da matéria seca, este foi moído para determinações química de $\mathrm{N}, \mathrm{P}, \mathrm{K}, \mathrm{Ca}$ e $\mathrm{Mg}$ conforme técnica descrita por SARRUGE \& HAAG (1974), feitas no Laboratório do Depto. de Ciência do Solo da ESALQ/USP.

$O$ delineamento usado foi de blocos ao acaso com 6 repetições em parcelas subdivididas, sendo usadas como variáveis para avaliar os efeitos dos tratamentos, altura de plantas, percentagem de plantas com dois lançamentos foliares emitidos, diâmetro do caule, produção de matéria seca.

\section{RESULTADOS E DISCUSSÃO}

O uso da seringa dosadora automática, para adubação líquida de mudas de seringueira, produzidas em sacos de plástico, mostrou-se viável pela praticidade e precisão nas quantidades aplicadas.

Observações quinzenais mostraram comportamentos variáveis entre tratamentos, para altura total de plantas a partir de $\mathbf{3 0}$ dias após a decepagem, onde a adubação feita 15 dias antes desta, promoveu antecipação na brotação, maior uniformidade e vigor do primeiro lançamento brotado, resposta desejável se o objetivo for a produção de mudas para plantio no campo, com o primeiro lançamento foliar completamente maduro (TABELA 2).

A partir de 60 dias da decepagem, houve uma antecipação na emissão do segundo lançamento foliar o que resultou em mais rápido crescimento das mudas adubadas com NPK aos 30 dias ( $+\mathbf{3 0}$ dias), superando os demais tratamentos a partir dos 90 dias, tornando-se mais evidente a diferença aos 105 dias (TABELA 2).

A adubação fracionada na data da decepagem e aos 30 dias depois, foi o segundo melhor tratamento, sendo ao contrário obtida a menor média da altura de plantas $(41,70 \mathrm{~cm})$, no tratamento adubado na data da decepagem dos porta-enxertos.

O efeito principal da aplicação de fósforo (adubação completa NPK), independentemente da data de aplicação, exerceu efeito positivo sobre a altura de plantas, se mostrando superiores aos demais tratamentos adubados somente com NK, dos 75 aos 105 dias após a adubação (TABELA 3).

Com relação aos efeitos das interações entre o uso de fósforo e as diferentes épocas de aplicação, sobre o crescimento em altura das plantas, foi obtida resposta significativa apenas para as plantas adubadas na época (0 dia), correspondente à data da decepagem, onde a aplicação de NK (ausência de P), foi estatisticamente superior à adubação completa NPK (presença de P). A comparação entre épocas dentro de $P$ (níveis 0 e 1) não mostrou resposta significativa do efeito de P (TABELA 4).

As adubações NPK e NK, feitas $\mathbf{3 0}$ dias depois da decepagem dos porta-enxertos, promoveu maior crescimento em altura, diâmetro do caule, percentagem de plantas com dois lançamentos foliares e peso total da matéria seca, mostrando-se superior aos demais tratamentos. 
TABELA 2 - Evolução da altura de plantas crescidas a pleno sol, com relação às épocas de aplicação de NPK (média de 24 plantas).

\begin{tabular}{ccccccc}
\hline \hline \multirow{2}{*}{$\begin{array}{c}\text { Epoca } \\
\text { de }\end{array}$} & 30 & 45 & 60 & 75 & 90 & 105 \\
\cline { 2 - 7 } Adubação & \multicolumn{5}{c}{ Altura total de plantas $(\mathrm{cm})$} \\
\cline { 2 - 7 } & \multicolumn{7}{c}{ Dias } \\
\hline-15 dias & $29,81 \mathrm{a}$ & $29,58 \mathrm{a}$ & $30,97 \mathrm{a}$ & $35,27 \mathrm{a}$ & $42,41 \mathrm{ab}$ & $43,97 \mathrm{~b}$ \\
0 dia & $26,79 \mathrm{a}$ & $31,49 \mathrm{a}$ & $32,98 \mathrm{a}$ & $35,00 \mathrm{a}$ & $39,47 \mathrm{~b}$ & $41,70 \mathrm{~b}$ \\
+15 dias & $27,25 \mathrm{a}$ & $28,27 \mathrm{a}$ & $28,79 \mathrm{a}$ & $34,72 \mathrm{a}$ & $39,56 \mathrm{~b}$ & $44,35 \mathrm{~b}$ \\
+30 dias & $25,76 \mathrm{a}$ & $32,40 \mathrm{a}$ & $33,40 \mathrm{a}$ & $42,22 \mathrm{a}$ & $52,33 \mathrm{a}$ & $56,02 \mathrm{a}$ \\
0 e 30 dias & $25,75 \mathrm{a}$ & $31,18 \mathrm{a}$ & $32,06 \mathrm{a}$ & $37,83 \mathrm{a}$ & $48,12 \mathrm{ab}$ & $51,70 \mathrm{ab}$ \\
\hline DMS & 5,638 & 6,675 & 5,872 & 7,865 & 10,180 & 1,059 \\
CV & 18,13 & 18,72 & 15,92 & 18,22 & 19,67 & 19,95 \\
\hline \hline
\end{tabular}

Tabela 3 - Efeitos dos níveis de fósforo sobre a altura média de plantas de seringueira (média de 24 plantas).

\begin{tabular}{ccccccc}
\hline \hline \multirow{2}{*}{ Níveis } & \multicolumn{7}{c}{ Altura total de plantas (cm) } \\
\cline { 2 - 7 } & \multicolumn{7}{c}{45} & 60 & 75 & 90 & 105 \\
\cline { 2 - 7 } & $27,06 \mathrm{a}$ & $31,55 \mathrm{a}$ & $32,49 \mathrm{a}$ & $39,10 \mathrm{a}$ & $48,15 \mathrm{a}$ & $51,72 \mathrm{a}$ \\
\hline 1 & $26,28 \mathrm{a}$ & $29,62 \mathrm{a}$ & $30,79 \mathrm{a}$ & $43,92 \mathrm{~b}$ & $40,61 \mathrm{~b}$ & $43,37 \mathrm{~b}$ \\
0 & 3,985 & 2,624 & 1,913 & 2,987 & 4,402 & 4,463 \\
\hline \hline
\end{tabular}

Entre as diferentes épocas de adubação, os maiores percentuais de plantas com dois lançamentos foliares, corresponderam aos tratamentos adubados aos 30 dias e $0-30$ dias (TABELA 5). Estes resultados, evidenciam que as adubações feitas aos 30 dias, quando o primeiro lançamento foliar se encontra em expansão, nos estádios $\mathrm{B}_{2} / \mathrm{C}$, tendem a acumular reservas, que serão mobilizadaspara promover a antecipação e o maior vigor do segundo lançamento foliar emitido, característica desejável na fase de produção de mudas. Ao contrário, a adubação feita na data de decepagem (0 dias), parece não ser recomendável, porque a ausência total de folhagem, pode haver restrições na absorção de água e sais minerais refletindo-se em menor crescimento, diâmetro do caule, peso total da matéria seca e percentual de plantas com dois lançamentos foliares emitidos (TABELA 5).

Para o peso da matéria seca, houve uma resposta positiva em todas as épocas de adubação, exceto para a aplicação na data de decepagem ( 0 dias) e ( + 15 dias).

A adubação completa NPK aos 30 dias e 0 - 30 dias, sobressaiu-se sobre os demais tratamentos para a percentagem de plantas com dois lançamentos foliares completamente maduros (TABELA 5). 


\section{ADUBAÇĀO DA SERINGUEIRA NO PERÍODO DE PÓS ENXERTIA. I: RELACIONADA À DATA...}

TABELA 4 - Efeitos das interações entre fósforo (presença e ausência) e épocas de aplicação sobre a altura de plantas (média de 24 plantas).

\begin{tabular}{|c|c|c|c|c|c|c|c|}
\hline \multirow{3}{*}{$\begin{array}{c}\text { Época } \\
\text { de } \\
\text { Adubação }\end{array}$} & \multirow{2}{*}{$\begin{array}{c}\text { Níveis } \\
\text { de }\end{array}$} & \multicolumn{6}{|c|}{ Altura total de plantas $(\mathrm{cm})$} \\
\hline & & 30 & 45 & 60 & 75 & 90 & 105 \\
\hline & $\mathbf{P}$ & \multicolumn{6}{|c|}{ Dias após a adubação } \\
\hline \multirow[t]{2}{*}{-15 dias } & 1 & $29,98 \mathrm{a} \mathrm{A}$ & 32,92 & 33,73 & 40,02 & 47,55 & 49,15 \\
\hline & 0 & $25,63 \mathrm{a} \mathrm{A}$ & 26,25 & 28,20 & 30,52 & 37,27 & 38,80 \\
\hline \multirow[t]{2}{*}{0 dia } & 1 & $23,67 \mathrm{a} \mathrm{A}$ & 30,05 & 32,32 & 33,57 & 38,53 & 49,15 \\
\hline & 0 & $29,92 \mathrm{a} \mathrm{B}$ & 32,93 & 33,65 & 36,43 & 40,42 & 42,70 \\
\hline \multirow[t]{2}{*}{+15 dias } & 1 & $28,03 \mathrm{aA}$ & 28,62 & 28,65 & 37,00 & 43,18 & 50,70 \\
\hline & 0 & $24,74 \mathrm{a} A$ & 27,92 & 29,03 & 32,45 & 35,93 & 38,00 \\
\hline \multirow[t]{2}{*}{+30 dias } & 1 & $27,65 \mathrm{a} A$ & 35,54 & 45,58 & 47,10 & 61,95 & 64,93 \\
\hline & 0 & $23,87 \mathrm{a} \mathrm{A}$ & 29,27 & 31,22 & 37,23 & 42,77 & 47,10 \\
\hline \multirow[t]{2}{*}{0 e 30 dias } & 1 & $23,98 \mathrm{a} \mathrm{A}$ & 30,62 & 32,25 & 37,72 & 49,55 & 53,13 \\
\hline & 0 & $27,52 \mathrm{aA}$ & 31,75 & 31,87 & 37,95 & 46,68 & 57,27 \\
\hline DMS $^{1}$ & & 7,975 & & & & & \\
\hline $\mathrm{DMS}^{2}$ & & 5,976 & & & & & \\
\hline
\end{tabular}

DMS $^{1}$ - Comparação entre épocas dentro de P pelo teste de Tukey, ao nível de $5 \%$ de probabilidade letra maíuscula

$\mathrm{DMS}^{2}$ - Comparação entre $\mathrm{P}$ dentro das épocas pelo teste de Tukey, ao nível de $5 \%$ de probabilidade letra minúscula

Com relação ao diâmetro do caule, a adubação feita aos 30 dias após a decepagem do porta-enxerto, foi superior apenas à adubação feita 15 dias antes da decepagem. Não sendo observada diferença entre as diferentes épocas de adubação para a var. altura do $2^{\circ}$ lançamento (TABELA 5).

Ficou evidenciado que a adubação fosfatada, independentemente da data de aplicação, mostrou resposta positiva sobre a percentagem de plantas com dois lançamentos foliares, emitidos aos 105 dias, o que evidencia a importância e a necessidade de adubação de mudas de seringueira no período de pós-enxertia, que antecede o plantio no local definitivo. As demais variáveis não foram afetadas pela presença ou ausência de $P$ nas adubações (TABELA 6).

\section{Quando avaliados os efeitos das} interações entre épocas, dentro de $P$ aplicado $e$ entre $\mathrm{P}$ (presença e ausência) dentro das diferentes épocas de aplicação, observou-se diferença significativa apenas para a variável diâmetro do caule, onde a ausência de $P$ na adubação feita, na data da decepagem foi estatisticamente superior à aplicação desse elemento.

A comparação entre as diferentes épocas mostrou que a adubação fosfatada (NPK), feita na data da decepagem foi inferior àquelas feitas dos 30 dias e 0-30 dias (TABELA 7).

Para as demais variáveis, obteve-se efeitos das diferentes épocas, não sendo significativas as respectivas interações ( $P$ dentro de épocas ou épocas dentro de P). 
TABELA 5 - Efeitos das diferentes épocas de adubação sobre altura do $2^{\circ}$ lançamento, percentagem de plantas com dois lançamentos foliares, diâmetro do caule e peso de matéria seca total (média de 24 plantas).

\begin{tabular}{ccccc}
\hline \hline \multirow{2}{*}{$\begin{array}{c}\text { de } \\
\text { Adubação }\end{array}$} & $\begin{array}{c}\text { Altura do } 2^{\circ} \text { Lan- } \\
\text { çamento }(\mathrm{cm})\end{array}$ & $\begin{array}{c}\text { \% de plantas com } \\
2 \text { Lançamentos }\end{array}$ & $\begin{array}{c}\text { Diâmetro do Caule } \\
(\mathrm{cm})\end{array}$ & $\begin{array}{c}\text { Peso da Matéria } \\
\text { Seca Total }(\mathrm{g})\end{array}$ \\
\cline { 2 - 5 }-15 dias & $18,02 \mathrm{a}$ & $62,50 \mathrm{bc}$ & $0,49 \mathrm{~b}$ & $13,23 \mathrm{ab}$ \\
0 dia & $17,12 \mathrm{a}$ & $41,67 \mathrm{c}$ & $0,51 \mathrm{ab}$ & $8,50 \mathrm{~b}$ \\
+15 dias & $17,19 \mathrm{a}$ & $72,92 \mathrm{~b}$ & $0,54 \mathrm{ab}$ & $0,96 \mathrm{~b}$ \\
+30 dias & $24,37 \mathrm{a}$ & $97,92 \mathrm{a}$ & $0,57 \mathrm{a}$ & $18,11 \mathrm{a}$ \\
0 e 30 dias & $21,29 \mathrm{a}$ & $97,92 \mathrm{a}$ & $0,55 \mathrm{ab}$ & $18,20 \mathrm{a}$ \\
\hline DMS & 10,268 & 23,138 & 0,0708 & 7,5928 \\
CV & 44,93 & 26,60 & 11,39 & 47,88 \\
\hline \hline
\end{tabular}

Médias seguidas da mesma letra, não diferem significativamente entre si pelo teste de Tukey, ao nível de $5 \%$ de probabilidade.

TABELA 6 - Efeitos dos níveis de fósforo sobre Altura do $2^{\circ}$ lançamento, percentagem de plantas com dois lançamentos, diâmetro do caule e peso total da matéria seca total (média de 24 plantas).

\begin{tabular}{ccccc}
\hline \hline \multirow{2}{*}{ Níveis de } & \multicolumn{4}{c}{ Variáveis } \\
\cline { 2 - 5 } & $\begin{array}{c}\text { Altura do } 2^{\circ} \text { Lan- } \\
\text { çamento }(\mathrm{cm})\end{array}$ & $\begin{array}{c}\text { \% de plantas com } \\
\text { 2 Lançamentos }\end{array}$ & $\begin{array}{c}\text { Diâmetro do Caule } \\
(\mathrm{cm})\end{array}$ & $\begin{array}{c}\text { Peso da Matéria } \\
\text { Seca Total }(\mathrm{g})\end{array}$ \\
\hline 1 & $21,27 \mathrm{a}$ & $80,83 \mathrm{a}$ & $0,52 \mathrm{a}$ & $15,81 \mathrm{a}$ \\
0 & $17,93 \mathrm{a}$ & $68,33 \mathrm{~b}$ & $0,54 \mathrm{a}$ & $11,39 \mathrm{a}$ \\
\hline DMS & 3,3891 & 9,8142 & 0,0199 & 6,3015 \\
\hline \hline
\end{tabular}

Médias seguidas da mesma letra, não diferem significativamente entre si pelo teste de Tukey, ao nível de $5 \%$ de probabilidade.

\section{CONCLUSÕES}

1. A prática usual de simples decepagem da parte aérea dos porta-enxertos, visando formar mudas ensacoladas com um a dois lançamentos maduros para plantio de seringais, na ausência de adubação, deve ser evitada na produção de mudas de seringueira.
2. Para produção de mudas de seringueira em sacos plásticos, usando como substrato o solo Podzolizado, variação Marilia, as doses de NK (200 ppm) e $\mathrm{P}(70 \mathrm{ppm})$, promoverama desenvolvimento adequado das plantas até a época necessária para o seu plantio no campo. 


\section{ADUBAÇĀO dA SERINGUEIRA NO PEŔODO dE PÓS ENXERTIA. I: RELACIONADA À DATA...}

TABELA 7 - Efeitos das interações entre fósforo (presença e ausência) e das epocas de aplicação sobre Altura do $2^{\circ}$ lançamento, percentagem de plantas com dois lançamentos, diâmetro do caule e peso total da matéria seca total (média de 24 plantas).

\begin{tabular}{cccccc}
\hline Épocas & $\begin{array}{c}\text { Niveis } \\
\text { de P }\end{array}$ & $\begin{array}{c}\text { Altura do } 2^{\circ} \text { Lan- } \\
\text { çamento }(\mathrm{cm})\end{array}$ & $\begin{array}{c}\text { \% de plantas com } \\
\text { 2 Lançamentos }\end{array}$ & $\begin{array}{c}\text { Diâmetro do } \\
\text { Caule (cm) }\end{array}$ & $\begin{array}{c}\text { Peso da Matéria } \\
\text { Seca Total (g) }\end{array}$ \\
\hline-15 dias & 1 & 19,50 & 77,00 & 0,51 ab A & 16,81 \\
& 0 & 16,53 & 50,00 & 0,47 a A & 9,65 \\
0 dia & 1 & 13,18 & 45,83 & 0,45 b B & 8,82 \\
& 0 & 21,07 & 37,50 & 0,57 a A & 8,19 \\
+15 dias & 1 & 20,94 & 83,33 & 0,54 ab A & 10,76 \\
& 0 & 13,43 & 62,50 & 0,54 ab A & 9,16 \\
+30 dias & 1 & 22,12 & 100,00 & 0,55 ab A & 22,15 \\
& 0 & 20,47 & 95,83 & 0,56 a A & 14,25 \\
$0-30$ dias & 1 & 22,12 & 100,00 & 0,55 ab A & 22,15 \\
& 0 & 20,47 & 95,83 & 0,56 a A & 14,25 \\
\hline DMS $^{1}$ & & - & - & 0,1001 & - \\
DMS $^{2}$ & & - & - & 0,0651 & - \\
\hline \hline
\end{tabular}

DMS ${ }^{1}$ - Comparação entre Épocas dentro de P pelo teste de Tukey, ao nível de $5 \%$ de probabilidade letra minúscula

DMS ${ }^{2}$ - Comparação entre P dentro das épocas pelo teste de Tukey, ao nível de $5 \%$ de probabilidade letra maiúscula

3. A adubação, na data da decepagem do portaenxerto ( 0 dias), não deve ser recomendada.

4. Se o objetivo for a produção de mudas com um lançamento foliar completamente maduro, deve ser feita a adubação 15 dias antes da decepagem da parte aérea do porta-enxerto, uma vez que, 60 dias após, as plantas estarão aptas para o plantio no local definitivo.

5. Se o objetivo for a produção de mudas para o plantio, com dois lançamentos foliares completamente maduros, a época ideal para aplicação de NPK será aos 30 dias depois da decepagem, quando as folhas do primeiro lançamento se encontram no estádio $B_{2}$.

6. Para a obtenção de mudas com o primeiro e segundo lançamentos foliares uniformes e vigorosos, as adubações com NPK deverão ser feitas aos 15 dias antes da decepagem da parte aérea do porta-enxerto e aos 30 dias após.

\section{REFERENNCIAS BIBLIOGRÁFICAS}

AMARAL, W. Deficiências de macronutrientes e de boro em seringueira (Hevea brasiliensis Muell. Arg.). Piracicaba, 1983. 44p. Dissertaçāo (Mestrado) - Escola Superior de Agricultura "Luiz de Queiroz", Universidade de São Paulo.

BUENO, N.; GASPAROTTO, C.; RODRIGUES, F.M.; ROSSETTI, A.G. Comparaçăo da eficiência técnicoeconômica de níveis de adubação com controle de doenças foliares na produção de mudas de seringueira. Manaus, EMBRAPA - Centro Nacional de Pesquisa de Seringueira e Dendê, 1984, 7p. (EMBRAPA / CNPSD. Comunicado Técnico, 33). 
BUENO, N. Alguns aspectos sobre a adubação da seringueira. In: SIMPÓSIO SOBRE A CULTURA DA SERINGUEIRA NO ESTADO DE SÃO PAULO, 1 ., Piracicaba, 1986. Anais... Campinas, Fundaçăo Cargill, 1986. p.83-93.

BUENO, N. Quantidade de alumínio no substrato afetando o desenvolvimento, a sintomogia de toxicidade, a concentração e 0 acúmulo de macro e micronutrientes em seringueira (Hevea spp). Piracicaba, 1987. 92p. Tese (Doutorado) - Escola Superior de Agricultura "Luiz de Queiroz", Universidade de São Paulo.

GUERRINI, I.A. Crescimento e recrutamento de macro e micronutrientes no período de quatro anos pela Hevea brasiliensis clone Fx 3864, na região de Rio Branco-AC. Piracicaba, 1983. 105p. Dissertação (Mestrado) - Escola Superior de Agricultura "Luiz de Queiroz", Universidade de São Paulo.

HAAG, H.P.; BUENO, N.; VIEGAS. I. de J.M.; PERERA, J. da P. Nutrição da seringueira. IV: Toxicidade de Boro em Hevea brasiliensis. Anais da Escola Superior de Agricultura "Luiz de Queiroz", Piracicaba, v.43, n.1, p.219-229, 1986.

INSTITUTO DE PESQUISAS AGROPECUÁRIAS DO NORTE-IPEAN. Adubação da seringueira em viveiro, em seringal em formação e em seringal em exploração. In: Relatorio de atividades $1972 / 1973$. Belém, 1973.

PEREIRA, J.P. Crescimento de mudas enxertadas de seringueira (Hevea spp) nas condições de sombra e a pleno sol, em função da adubação nitrogenada $e$ potássica, na presença e ausência da fosfatada e de ácido giberélico, em solo Podzolizado, variação Marilia. Piracicaba, 1990. 140p. Tese (Doutorado) Escola Superior de Agricultura "Luiz de Queiroz", Universidade de São Paulo.
PRADO, E.P.; MORAES, F.I.O. Adubação em plântulas enviveiradas de seringueira. In: CENTRO DE PESQUISAS DO CACAU. Informe Técnico 1968/1969. Itabuna, 1969. p.128-129.

REIS, F.I.; SOUZA, L.F.S.; CALDAS, R.C. Efeito da adubação NPK da calagem no crescimento de plântulas enviveiradas de seringueira. Revista Theobroma, Itabuna, v.7, n.2, p.35-40, Abr./Jun., 1977.

RUBBER RESEARCH INSTITUTE OF MALAYSIA. Annual Report 1972. Kuala Lumpur, 1973. 158p.

VALOIS, A.C.C.; BERNIZ, J.M.J. Adubação mineral em viveiro de seringueira. Manaus, Instituto de Pesquisas Agropecuárias da Amazônia Ocidental, 1974. p.25-33. (Boletim Técnico, 4).

VIEGAS, I. de J.M. Doses de NPK em viveiro de Hevea spp na obtenção de plantas aptas para enxertia em Latossolo Amarelo textura média, na Itha de Mosqueiro-PA. Piracicaba, 1985. 71p. Dissertação (Mestrado) - Escola Superior de Agricultura "Luiz de Queiroz", Universidade de São Paulo.

VIEGAS, I.J.M.; CUNHA, R.L.M. Avaliação da fórmula comercial de adubação $\mathrm{N}_{2} \mathrm{O}_{s}, \mathrm{~K}_{2} \mathrm{O}, \mathrm{MgO} \mathrm{em}$ viveiro de seringueira. In: SEMINÁRIO NACIONAL DA SERINGUEIRA, 3., Manaus, 1980. Anais... Manaus, MIC/SUDHEVEA, 1980. v.2, p.874-888.

VIEGAS, I. de J.M.; HAAG, H.P.; BUENO, N.; PEREIRA, J. da P. Nutrição mineral da seringueira. XII. Absorção de macro e micronutrientes nos primeiros 240 dias. Scientia Agricola, Piracicaba, v.49, n.especial, p.41-52, 1992.

Trabalho enviado para publicação em 12.11 .91

Trabalho aceito para publicação em 03.02 .93 